\title{
ANALYSIS OF THE SUPERPHENIX START-UP TESTS WITH APOLLO-3: FROM ZERO POWER ISOTHERMAL CONDITIONS TO DYNAMIC POWER TRANSIENT ANALYSIS
}

\author{
Sciora Pierre $^{1}$, Garcia Elias ${ }^{1}$, Rimpault Gerald ${ }^{1}$, Droin Jean-Baptiste ${ }^{2}$ and Pascal Vincent ${ }^{2}$ \\ ${ }^{1}$ CEA, DEN, SPRC, LE2C, F-13108 Saint-Paul-Lez-Durance, France \\ ${ }^{2}$ CEA, DEN, SESI, LCOS, F-13108 Saint-Paul-Lez-Durance, France
}

pierre.sciora@cea.fr, gerald.rimpault@cea.fr, elias-yammir.garcia-cervantes@cea.fr, jeanbaptiste.droin@cea.fr, vincent.pascal@cea.fr

\begin{abstract}
Sodium-cooled Fast Reactors (SFRs) remain a potential candidate to meet future energy needs. In addition, the SFRs experimental feedback is considerable, for instance, the French research program has considered experimental facilities including the Superphénix which has emerged as a transition to commercial deployment. In this paper a set of tests from the Superphénix start-up are reanalyzed with new tools, considering APOLLO-3 and TRIPOLI-4 (respectively deterministic and stochastic codes) for neutron physics evaluation, GERMINAL-V2 for the fuel irradiation behavior and CATHARE-3 for the thermalhydraulics modelling. Neutron physics evaluations are performed for the main control rod worth and the Doppler Effect, both measured under isothermal conditions at Superphénix start-up. A good agreement is obtained for these tests, which were purely neutronic tests. Next, the core temperature distribution is evaluated at nominal conditions, where larger discrepancies are observed. However, these deviations are related to the measurement of the fuel assemblies, which have a larger than expected uncertainty. Finally a transient, consisting of a negative reactivity insertion, is analyzed to assess the dynamic core behavior. A good agreement is obtained during the reactivity insertion, however the thermal-hydraulic model has to be improved, namely the vessel model, which is considered as a 0-D volume.
\end{abstract}

KEYWORDS: Superphenix, start-up, power transient, Apollo-3 validation

\section{INTRODUCTION}

The development of nuclear energy considers various concepts and prototypes to be deployed in the incoming decades as a solution to the current challenges. Six different candidates stand out for their promising performance, among them, the Sodium-cooled Fast Reactor (SFR) is an outstanding concept with considerable experimental feedback.

Various countries have committed themselves to the development of SFR, in particular France. In the course of its research and development program it has considered three facilities with different objectives: Rapsodie, Phénix and Superphénix. In particular, Superphénix was designed with a commercial approach to serve as a transition design from experimental facilities towards an SFR commercial deployment [1].

In this paper we are especially interested in Superphénix, as its experimental feedback is unique in terms of its large size core. During the Superphénix start-up, various tests were performed to asses the safety 
criteria of the core [2] [3]. Thus, different power conditions were considered for the core, starting from isothermal conditions (zero-power conditions) to power conditions (obtained by a progressive increase in power). Under power conditions, different tests were performed, for instance the dynamic core behavior was evaluated by a transient test.

In this paper, the authors aim to reproduce one of these transient tests performed during the start-up program in power conditions in Superphénix. It considers a Negative Reactivity Insertion achieved by inserting the control rods in three different steps. In order to reproduce such a test, we need a correct neutronic model of the core and an appropriate hypothesis on the core temperature operation.

In order to reproduce this test, we will rely on the use of novel calculation tools, for instance for the neutronic analysis we consider the use of the stochastic TRIPOLI-4 [4] code (5000 batches of 20000 neutrons) and the deterministic APOLLO-3 code [5] with the newly developed calculation schemes [6] [7] and the nuclear data library JEFF3.1.1. For core temperature operation, we rely on the use of GERMINAL-V2 code to get the best estimated fuel temperature in CATHARE-3 by adjusting the available input parameters, while CATHARE-3 is used for the thermal-hydraulics modelling (coupling the neutronic by means of a point kinetic module), with the best-estimate calculation schemes usually used at CEA (7 derivations).

\section{SUPERPHÉNIX START-UP PROGRAM}

The Superphénix was a $3000 \mathrm{MW}_{\text {th }}$ SFR reactor built in the south of France as part of a European consortium between Germany, Italy and France. It considered a commercial approach with intermittent operation between 1986 and 1997. Feedback from its operation has made it possible to assimilate the stakes of a large scale SFR.

The Superphénix start-up core was composed of 190 internal fuel assemblies, 168 external fuel assemblies and 222 fertile assemblies [1]. The control system consisted of the Main Control System SCP (Système de Commande Principale in French) which included 21 assemblies divided into two curtains (see Figure 1). Alternatively, the back-up control rod system SAC (Système d'Arrêt Complémentaire in French) in Superphénix considered 3 assemblies located in the inner core to assure the core shutdown in case of emergency.

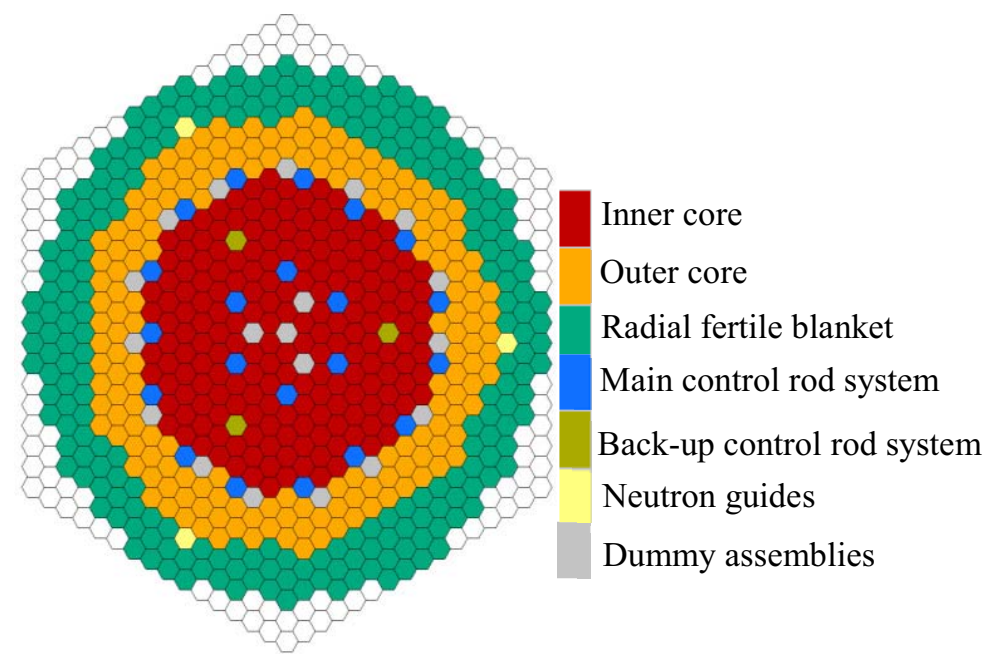

Figure 1. Superphénix start-up core layout 
During the start-up program, different core characteristics were measured. First at isothermal state (zeropower conditions), reactivity measurements were performed by loading a particular assembly called DIMEP-B, which considered three axial fission chambers along the core height [1]. In this step, measurements of the control rod worth, the flux distribution of the core and the Doppler constant was performed.

Secondly, during the rise in power phase the core temperature distribution was measured by the outlet thermocouples placed at the output of each fuel assembly. Besides, the dynamic behavior of the core was assessed by a set of transients performed at power conditions, in particular the Negative Reactivity Insertion (NRI) transient.

Previous research concerning the Superphénix consisted in the development and validation of the start-up tests with the TRIPOLI-4 Monte Carlo code [8]. Besides the core flux distribution at isothermal conditions has been assessed with multiple codes using different nuclear data [9]. Currently our objective is to reproduce the core dynamic behavior by analyzing the NRI test. This requires a good description of the core neutronic characteristics, in particular the rods worth, the Doppler constant and the power distribution of the core, as they are strongly related to the NRI test.

For this reason, this paper considers a set of the Superphénix start-up tests at isothermal state and at power conditions, in particular the following tests, to end with the NRI test:

- Control rod worth

- Doppler constant

- Nominal power temperature distribution and

- Negative Reactivity Insertion (NRI).

The following Chapter discusses each of these tests, providing experimental characteristics and specifications on modelling considerations.

\section{ANALYSIS AND RESULTS}

\subsection{Main control rod (SCP) worth measurement}

The control rod worth was measured in the CMP (Superphénix start-up core, Cour de Montée en Puissance in French), recording the measured count rates of the DIMEP-B assembly and translating them into reactivity through the Modified Source Multiplication (MSM) Method. Three different positions of the SCP were considered to determine its worth, the inserted SCP position (SCP $\downarrow$ ), the critical SCP position (SCP Zc) and the extracted SCP position (SCP $\uparrow$ ). The first two were measured directly from the fission chambers count rates, while the extracted SCP position was obtained using Equation 1.

$$
\rho_{\text {res }}=\rho(\downarrow)\left[1-\frac{1}{f}\right]
$$

Where $\rho(\downarrow)$ is the measured reactivity of inserted SCP,

$f$ represents the reactivity fraction released of the SCP.

The SCP worth was determined using the codes TRIPOLI-4 and APOLLO-3, the estimates of which are presented in Table I. APOLLO-3 considers the calculation scheme validated in reference [6]. There is clearly an overestimation of reactivity with both codes for all SCP positions. This reactivity overestimation appears to be a systematic nuclear data bias related to the use of JEFF 3.1.1. 
Table I. Reactivity of the core for different SCP positions and discrepancies with the measurements

\begin{tabular}{|c|c|c|c|}
\hline Measurement & $3844 \pm 264$ & 0 & $-4414 \pm 294$ \\
\hline Code & SCP $\uparrow$ & SCP Zc & SCP $\downarrow$ \\
\hline TRIPOLI-4 & $4242(398)$ & $374(374)$ & $-4046(369)$ \\
\hline APOLLO-3 & $4305(461)$ & $381(381)$ & $-4050(364)$ \\
\hline
\end{tabular}

The Calculation - Experiment $(\mathrm{C}-\mathrm{E}$ in $\mathrm{pcm})$ for the main control rod worth is shown in Figure 2. Both evaluations are in good agreement with measurements, within the experimental uncertainty range. However, a slightly larger discrepancy is found with APOLLO-3 than with TRIPOLI-4, if compared to measurements.
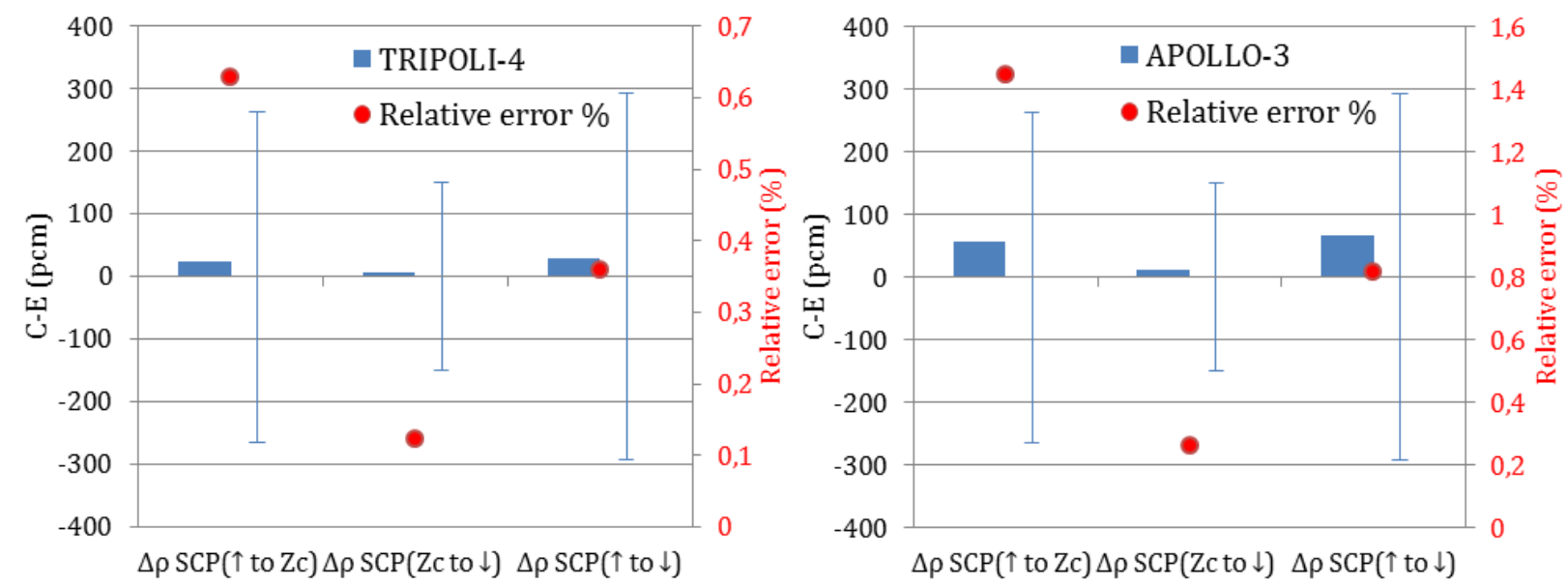

Figure 2. Control rod worth C-E in pcm for TRIPOLI-4 (left) and APOLLO-3 (right)

Small deviations from the measurements are a verification of our model. A more detailed evaluation of this model and other comparisons to the experiment can been found in the reference [8]. This validates the first step of this work to evaluate the NRI transient.

\subsection{Doppler test}

The Doppler Effect is one of the parameters of the core that concerns its dynamic behavior; knowledge of it is therefore important for safety reasons. In the Superphénix, after successful start-up, a test was performed to determine the Doppler effect of the core [10]. In isothermal conditions, the reactivity variation of a core can be described as function of the temperature, as shown in Equation 2, by considering a logarithmic temperature dependence of the Doppler Effect.

$$
d \rho=k d T+K_{D} \frac{d T}{T},
$$

where $k$ represents the expansion coefficient $\left(\mathrm{pcm} /{ }^{\circ} \mathrm{C}\right)$ and $K_{D}$ is the Doppler constant. Thus, the change in reactivity can be considered as the contribution of two elements; the first is directly related to the expansion of the material including the fuel, which in this case is considered free in the cladding, since this test was carried out with fresh fuel. The second effect is related to the Doppler Effect of the fuel and the core structures; however the measurements do not distinguish between the fuel and structural Doppler Effect. 
In Superphénix, the test to determine the Doppler Effect consisted of a decrease in temperature from $400^{\circ} \mathrm{C}$ to $180^{\circ} \mathrm{C}$ in isothermal conditions. Measurements were taken every hour, i.e. every two or three degrees to plot the experimental curve. The successive insertion of control rods compensated the reactivity increase as the core temperature decreased and the contribution of the linear and logarithm part of this change in reactivity was extracted, following the previous equation.

Table III. Evaluation of $k$ and $K_{D}$, and comparison to the values obtained from the measurements

\begin{tabular}{|c|c|c|}
\hline Average between $400{ }^{\circ} \mathrm{C}$ and $180^{\circ} \mathrm{C}$ & Measure & Calculation, (C/E) \\
\hline Overall isothermal coefficient $\left(\mathrm{pcm} /{ }^{\circ} \mathrm{C}\right)$ & $2.87 \pm 10 \%$ & $2.927(1.019)$ \\
\hline Expansion component $\left(\mathrm{pcm} /{ }^{\circ} \mathrm{C}\right)$ & $0.74+20 \%$ & $0.654(0.88)$ \\
\hline Doppler constant $\mathrm{K}_{\mathrm{D}}(\mathrm{pcm})$ & $1256 \pm 9 \%$ & 1263 \\
\hline
\end{tabular}

In sake to better understand the Doppler constant, it was decomposed to observe the contribution of each core region as well as the contribution of the steel to the measured effect. The estimates are presented in Table IV, for the contributions of the different core regions. It should be noted that the steel Doppler Effect accounts for nearly $10 \%$ of the total effect.

Table IV. Decomposition of the Doppler by mediums for fuel and steel contributions

\begin{tabular}{|c|c|c|c|c|c|c|}
\hline Region & \multicolumn{2}{|c|}{$\Delta \rho$ Fuel } & \multicolumn{2}{c|}{$\Delta \rho$ Fuel and Steel } & \multicolumn{2}{c|}{$\begin{array}{c}\Delta \rho \text { Steel } \\
\text { contribution }\end{array}$} \\
\hline & $\mathrm{pcm}$ & $\%$ & $\mathrm{pcm}$ & $\%$ & $\mathrm{pcm}$ & $\%$ \\
\hline Inner core & 319 & 70.4 & 350 & 70.41 & 31 & 67.39 \\
\hline Outer core & 99 & 21.8 & 109 & 21.94 & 10 & 21.85 \\
\hline Both cores & 420 & 92.7 & 464 & 93.34 & 44 & 95.65 \\
\hline Axial bottom blanket & 14 & 3.09 & 16 & 3.21 & 2 & 4.34 \\
\hline Axial upper blanket & 11 & 2.42 & 11 & 2.21 & 0 & 0 \\
\hline Axial blankets & 25 & 5.51 & 26 & 5.23 & 1 & 2.17 \\
\hline Radial blanket & 10 & 2.20 & 11 & 2.21 & 1 & 2.17 \\
\hline Axial and radial blankets & 35 & 7.72 & 37 & 7.44 & 2 & 4.34 \\
\hline Total & 453 & 100 & 497 & 100 & 46 & 100 \\
\hline
\end{tabular}

The good evaluation of the Doppler constant, even if it's only in isothermal states, validates our model and the second step of our work.

\subsection{Nominal power temperature distribution}

The core power distribution was measured in Superphénix y measuring the sodium temperature at the subassemblies outlet using TRTC (TRaitement des Temperatures du Cœur in French) thermocouples. The main objective of these devices was to perform core supervision by calculating the individual assembly power, the linear power and the clad temperature in operation [11].

In the Superphénix core, a total of 944 thermocouples were placed in 376 subassemblies corresponding to the fissile cores (inner and outer) and the first fertile assembly row. When the core entered nominal operations, $\Delta \mathrm{T}_{\mathrm{c}}$ was obtained, as the difference between the inlet core temperature (measured at the 
primary pump outlet) and the average of the TRTC measurement at the outlet of the core. The power distribution per assembly can be obtained from the Equation 3.

Where, $\mathrm{C}_{\mathrm{p}}$ is the sodium heat capacity

$$
P_{i}=C_{p} Q_{i} Q_{p} \Delta T_{i}
$$

$Q_{i}$ is the sodium flowrate per assembly as a fraction of the primary flowrate

$\mathrm{Q}_{\mathrm{p}}$ is the primary flowrate

The comparison between evaluations with APOLLO-3 (including gamma heating) and measurements is presented in Figure 3. Discrepancies for the core temperature distribution are within $4 \%$ to $8 \%$, with an overestimation at the center and an underestimation at the core periphery.
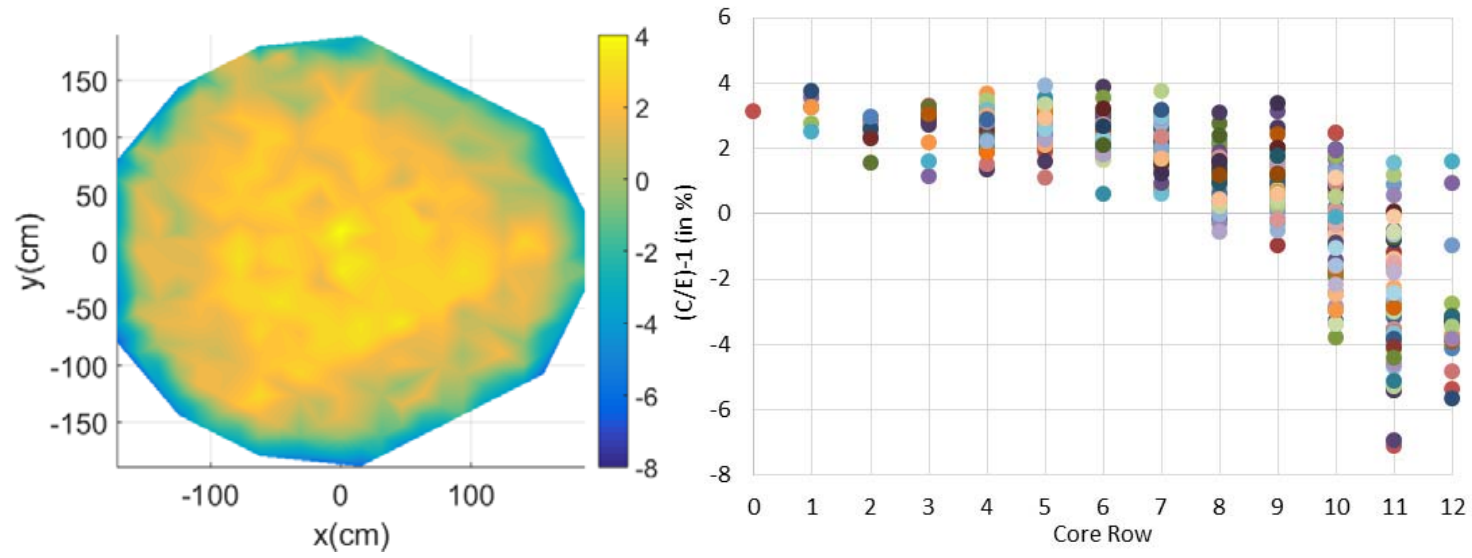

Figure 3. Core power distribution discrepancies for the whole core (left) and per core rows (right)

These discrepancies are in fact larger than those observed in previous analysis for the flux distribution tests in isothermal conditions [9]. Indeed, in Superphénix, anomalies in the thermal-hydraulic measurements were present as indicated in reference [12] relating to the assembly design. This increases the experimental measurements uncertainty and explains the larger inconsistencies found for these tests. Now that the main parameters of the NRI transient have been evaluated and compared to the experimental values one by one, the transient itself is evaluated and compared to the experience.

\subsection{Negative Reactivity Insertion}

The NRI tests consisted of the insertion of negative reactivity in three steps driven by the control rods. The objective was to observe the core feedback behavior during such perturbation. This was reproduced with CATHARE-3 which represented the systems involved in the primary and secondary circuits, with boundary conditions for the tertiary circuit. The elementary feedback coefficients were produced with APOLLO-3 with the temperature operating assumption of GERMINAL-V2.

The measurements are compared with the CATHARE-3 evaluations, starting with the core power in Figure 4. Leaving aside the instabilities observed before the transient in the experimental curves, the CATHARE-3 shows good agreement for core power during the transient for each negative reactivity step insertion. The amplitude of the insertion is related to the frequency of the recorded values: every second for the measurement, and less than $0.1 \mathrm{~s}$ for the calculation. The peak of power is therefore more important with CATHARE-3. 
However, after the insertion of negative reactivity, the estimated core power smoothly increases until it is stabilized at $1450 \mathrm{MW}$. Compared to the measurements, the CATHARE-3 calculation does not faithfully reproduce the core power after the reactivity insertion since the vessel is considered as a 0 -D volume. As explained in references [2] and [13] the vessel thermal expansion plays an important role, and its contribution is observed when a slight decrease in core power is recorded (between $1000 \mathrm{~s}$ and $1500 \mathrm{~s}$ ).

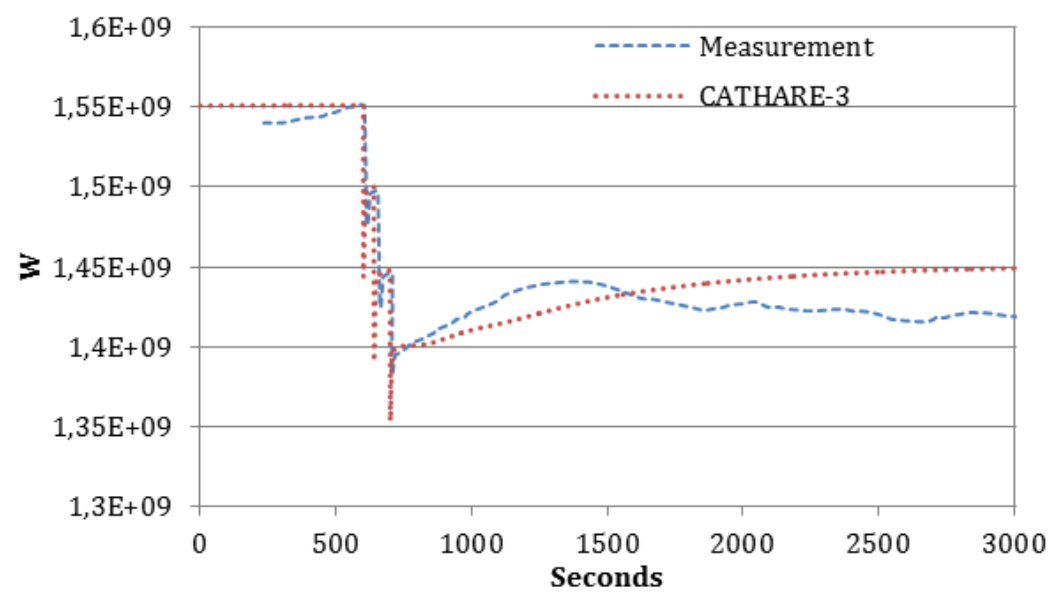

Figure 4. Core power during NRI transient

The core inlet temperature and the change between the inlet and outlet core temperature ( $\Delta$ Tcore) are shown in Figure 5. The inlet temperature decreases over time of about $-8^{\circ} \mathrm{C}$ with CATHARE-3 which is in good agreement with the experimental measurements. Finally, the change between the core inlet and outlet temperature is overestimated by CATHARE- 3 (about $4{ }^{\circ} \mathrm{C}$ ), and during the transient, $\Delta$ Tcore shows a consistent temperature decrease of about $10{ }^{\circ} \mathrm{C}$. However, after insertion of the three antireactivity steps, a constant and steady increase of $\Delta$ Tcore is observed with CATHARE-3, while the experimental results show an increase of $\Delta$ Tcore followed by a slight decrease and stabilization. Therefore, as previously mentioned, the improvement of the vessel model definition in CATHARE-3 is necessary for the improvement of the interpretation of this test, these remain as further research.
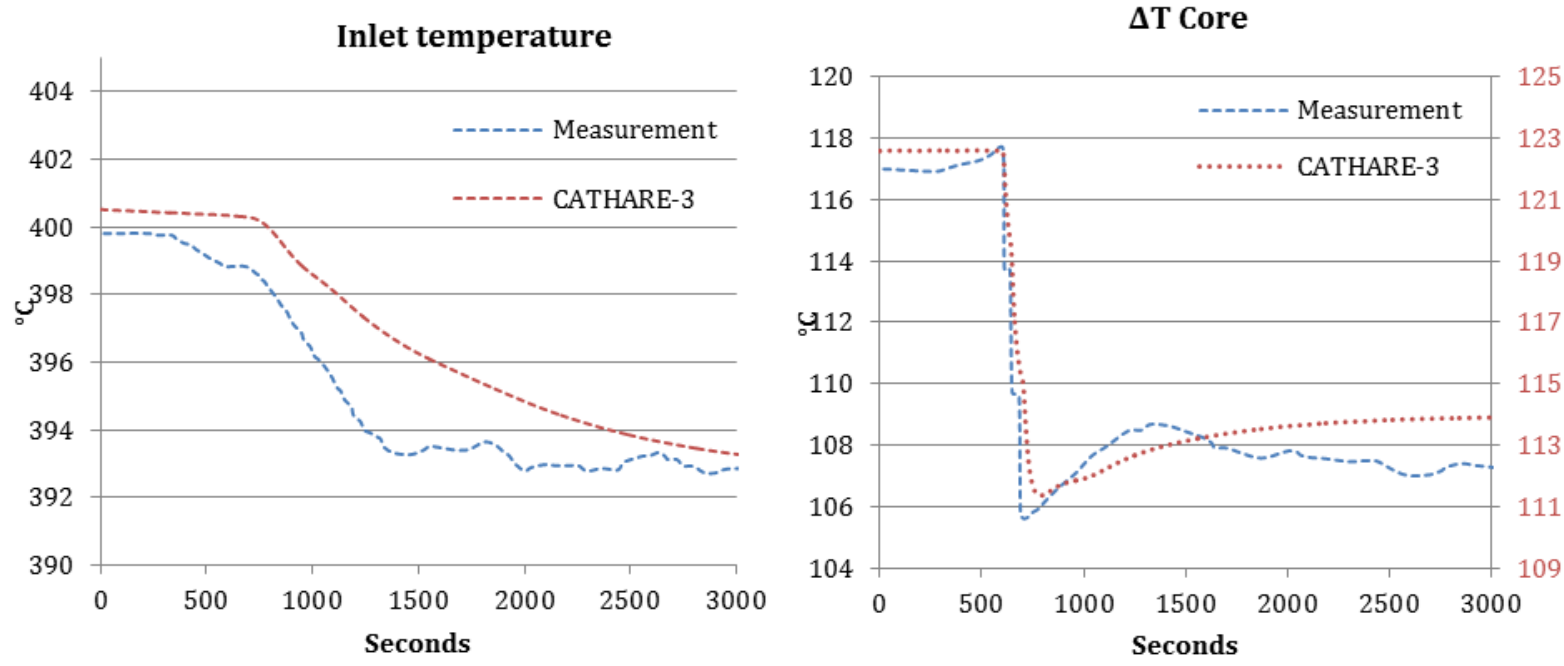

Figure 5. Inlet temperature (left) and $\Delta T$ Core (right) during the NRI transient. 


\section{CONCLUSIONS}

This paper aimed at reproducing the NRI test, which requires neutronic, thermo-mechanic and system models. The calculation tools APOLLO-3, GERMINAL-V2 and CATHARE-3 are used in this work. To validate the model step by step, the neutronic parameters, such as the rod worth and the Doppler constant are evaluated in isothermal conditions. Further validations are performed in the references [8] [9] [14] . Then, the power distribution is evaluated and compared to the thermocouples measurements.

The NRI test evaluation with CATHARE-3, based on the data evaluated by APOLLO-3 and GERMINAL-V2 shows small deviations at the beginning of the test. During the second part of the transient, the discrepancies are larger, due to the simplified model of vessel that is used. This will be improved in the next stage of this work.

\section{REFERENCES}

[1] J. Gourdon, B. Masnage, J. L. Voitellier and M. Suescun, "An Overview of Superphenix Commissioning Tests," Nuclear Science and Engineering, pp. 1-10, 1990.

[2] P. Bergeonneau, M. Vanier, M. Favet, J. De Antoni, K. Essig and J. P. Adam, "An Analysis of the Dynamic Behavior of the Core," Nuclear Science and Engineering, vol. 106, pp. 69-74, 1990.

[3] J. C. Gauthier, J. C. Cabrillat, G. Palomiotti, M. Salvatores, M. Giese, M. Carta and J. P. West, "Measurement and Predictions of Control Rod Worth," Nuclear Science and Engineering, pp. 18-29, 1990.

[4] E. Brun, F. Damian, C. M. Diop, E. Dumonteil, F. X. Hugot, C. Jouanne, Y. K. Lee, F. Malvagi, A. Mazzolo, O. Petit, J. C. Trama, T. Visonneau and A. Zoia, "Tripoli-4®, CEA, EDF and AREVA reference Monte Carlo code," Annals of Nuclear Energy, pp. 151-160, 2015.

[5] P. Archier, J.-M. Palau, J.-F. Vidal, V. Pascal, G. Rimpault, B. Roque and S. Santandrea, "New reference APOLLO3 C Calculation scheme for sodium cooled fast reactors: from sub-assembly to fullcore calculations," in PHYSOR 2016, Sun Valley, ID, 2016.

[6] H. Guo, E. Garcia, B. Faure, L. Buiron, P. Archier, P. Sciora and G. Rimpault, "Advanced method for neutronic simulation of control rods in sodium fast reactors: Numerical and experimental validation," Annals of Nuclear Energy, pp. 90-100, 2019.

[7] B. Faure, P. Archier, J. Vidal et L. Buiron, «A 2D/1D Algorithm for Efective Cross-Section Feneration in Fast Reactor Neutronic Transport Calculations,» Nuclear Science and Engineering, pp. 40$51,2018$.

[8] E. Garcia, P. Sciora and G. Rimpault, "Evaluation of the neutronic Superphenix start-up commissioning tests with TRIPOLI4," Annals of Nuclear Energy, pp. 366-374, 2019.

[9] E. Garcia, P. Sciora, T. Kooyman, G. Rimpault, H. Guo and B. Faure, "Flux distribution of the Superphénix start-up core for the validation of neutronic codes," Annals of Nuclear Energy, vol. 133, pp. 889-899, 2019.

[10] M. Vanier, P. Bergeonneau, J. C. Gauthier, M. Jacob, J. de Antoni, E. Gesi, P. Peerani and J. P. Adam, "Superphénix Reactivity and Feedback Coefficients," Nuclear Science and Engineering, vol. 106, pp. 30-36, 1990.

[11] J. P. Girard, J. P. Trapp and P. Renaud, "Core parameter monitoring on French LMFBR," in Instrumentation for supervision of core in fast breeder reactors, Kalpakkam, 1989.

[12] J. P. Pages, G. Fancois and R. Vidard, "Coolant Mixing Phenomena Influencing Measurements of Core Coolant Temperature Rises," Nuclear Science and Engineering, vol. 106, pp. 75-80, 1990.

[13] K. Mikityuk and M. Schikorr, "New transient analysis of the Superphénix start-up tests," in Proceedings of International Conference on Fast Reactors and Related Fuel Cylces: Safe Technologies and Sustainable Scenarios (FR13), Paris, France, 2013.

[14] E. Garcia, P. Sciora and G. Rimpault., "Analysis of the feedback coefficients of the Superphénix start-up core with APOLLO3," in ICAPP, Juan-Les-Pins, 2019. 